\title{
Protective effect of carboxymethyl-glucan (CM-G) against DNA damage in patients with advanced prostate cancer
}

\author{
Marciane Magnani ${ }^{1}$, Raul Jorge Hernan Castro-Gomez ${ }^{1}$, Mateus Prates Mori ${ }^{2}$, Hellen Kuasne ${ }^{2}$, \\ Emerson Pereira Gregório ${ }^{3}$, Farid Libos Jr. ${ }^{3}$ and Ilce Mara de Syllos Cólus ${ }^{2}$ \\ ${ }^{I}$ Departamento de Ciência e Tecnologia de Alimentos, Universidade Estadual de Londrina, Londrina, \\ PR, Brazil. \\ ${ }^{2}$ Departamento de Biologia Geral, Universidade Estadual de Londrina, Londrina, PR, Brazil. \\ ${ }^{3}$ Instituto do Câncer de Londrina, Londrina, PR, Brazil.
}

\begin{abstract}
Carboxymethyl-glucan (CM-G) is a soluble derivative from Saccharomyces cerevisiae $(1 \rightarrow 3)(1 \rightarrow 6)-\beta-D$-glucan . The protective efficiency of CM-G against DNA damage in cells from patients with advanced prostate cancer (PCa), and undergoing Androgen Deprivation Therapy (ADT), was evaluated. DNA damage scores were obtained by the comet assay, both before and after treatment with CM-G. The reduction in DNA damage, ranging from $18 \%$ to $87 \%$, with an average of $59 \%$, was not related to the increased number of leukocytes in peripheral blood. The results demonstrate for the first time the protective effect of $C M-G$ against DNA damage in patients with advanced PCa. Among smokers, three presented the highest reduction in DNA damage after treatment with CM-G. There was no observable relationship between DNA damage scores before and after treatment, and age, alcoholism and radiotherapy.
\end{abstract}

Key words: antioxidant, $\beta$-D-glucan, carboxymethyl-glucan, prostate cancer.

Received: May 28, 2010; Accepted: September 6, 2010.

$\beta$-D-glucan from the cell wall of Saccharomyces cerevisiae is a polymer composed of repeating glucose units, and organized into a central skeleton linked by $\beta$ $(1 \rightarrow 3)$ glycosidic bonds, with side chains of variable sizes joined by $\beta(1 \rightarrow 6)$ linkages (Di Luzio et al., 1979). As the benefits arising from the biological activity of $(1 \rightarrow$ $3)(1 \rightarrow 6)-\beta$-D-glucan are limited by its insolubility in water, studies are under way with derivatives of this polymer in an attempt to improve its availability. Soluble derivatives have additional advantages when administered in vivo, such as the absence of toxicity and adverse effects (Miadaková et al., 2005). Moreover, derivatization may even enhance certain biological properties, such as antioxidant and immunomodulation activities (Chen and Seviour, 2007; Xu et al., 2009). Another important factor is the maintenance of bioactivity, since $(1 \rightarrow 3)(1 \rightarrow 6)-\beta$-D-glucan soluble derivatives can cross the gastrointestinal wall without causing damage to the digestive system, even when orally administered (Chorvatovicová et al., 1996; Rice et al., 2005).

Carboxymethyl-glucan (CM-G), one of the most studied among the soluble derivatives of $S$. cerevisiae

Send correspondence to Marciane Magnani. Departamento de Ciência e Tecnologia de Alimentos, Universidade Estadual de Londrina, Rod Celso Garcia Cid, PR 445, km 380, Campus Universitário, Caixa Postal 6001, 86051-990 Londrina, PR, Brazil. E-mail: magnani2@gmail.com.
$(1 \rightarrow 3)(1 \rightarrow 6)-\beta$-D-glucan, has been shown to possess significant bioprotective properties, such as antimutagenic, antigenotoxic, antioxidant, and anticancer activities (Chorvatovicová et al., 1996; Babincová et al., 2002; Slamenová et al., 2003; Miadaková et al., 2005). The main mechanism proposed for these protective effects of CM-G is the capability of scavenging reactive oxygen species (Kogan et al., 2005), even at concentrations as low as $30 \mu \mathrm{M}$ (Babincová et al., 2002).

Prostate cancer (PCa) is the sixth most common cancer in the world, and represents about $10 \%$ of all cancers diagnosed. In Brazil, it is estimated that 49.530 new cases were diagnosed in 2009. Excluding non-melanoma skin cancer, it is the most frequent type of cancer in males and is prevalent countrywide, and counts with the second highest mortality rate in Brazil (National Cancer Institute of Brazil, 2010).

While a man with localized PCa is more likely to die from other comorbidities, the probability of death from $\mathrm{PCa}$ exceeds other causes when clinical metastases occur. At this stage, the aims of medical treatment are to increase the period of short-term survival of patients and, above all, to improve the quality of life, which often declines with progression of the disease. The standard treatment for advanced $\mathrm{PCa}$ is Androgen Deprivation Therapy (ADT), during which the administration of hormone analogues of a 
gonadotropin-releasing hormone (GnRH) leads to receptor desensitization, thus inhibiting the release of $\mathrm{LH}$ and $\mathrm{FSH}$, and resulting in chemical castration (Hellerstedt and Pienta, 2002).

The complications arising from chronic treatment, in addition to advanced age and fixed lifestyle habits, make patients with advanced PCa even more vulnerable. Therefore, the use of innocuous, naturally bioactive compounds, capable of improving the quality of life of these patients can be a befitting alternative. Simulations of reactions that occur in the human body due to the administration of CM-G have been reported in several experimental models, although evaluation in humans is scarce. Our goal in this study was to evaluate the possible protective effects of CM-G against DNA damage in peripheral lymphocytes of patients with advanced PCa. The nonrandomly selected target population expressed a clinical cancer scenario aggravated by age and lifestyle habits.

This study was undertaken after receiving approval from the Ethics Committee for Research Involving $\mathrm{Hu}-$ mans, under registration number NTC406800007 in the records of the Brazilian Information on Ethics in Research Involving Humans (SISNEP). Patients at the Londrina Cancer Institute (ICL), with a histological diagnosis of stage T3 $(\mathrm{n}=7)$ and T4 $(\mathrm{n}=13)$ prostate adenocarcinoma according to TNM staging (AJCC/UIAC, 2010), and undergoing androgen deprivation therapy (ADT) with goserelin acetate, were included in this study, after signing a written informed-consent. Individual information was collected by a face-to-face questionnaire (Carrano and Natarajana, 1988). The patients were kept under observation in order to check for possible side effects from CM-G administration.

CM-G with substituition degree (DS) 0.8 was obtained from $S$. cerevisiae insoluble $\beta$-glucan (Magnani et al. 2009). $20 \mathrm{mg}$ of CM-G, with starch as the excipient vehicle, were inserted into gelatin capsules. This procedure was carried out by Vico Farma ${ }^{\circledR}$ (National Health Surveillance Agency in Brazil number 136420-0). Bottles containing between 28 and 35 capsules were labeled with instructions for use. The variable number of capsules was to aid in controlling consumption by patients, return of the bottle being requested after the end of treatment. After daily administration of one capsule of CM-G (Demir et al., 2007), during a period of 28 days, the returned bottle should contain between zero and seven capsules, depending on the initial amount received by each patient.

Peripheral venous blood samples were collected, in a state of fasting, on the $1^{\text {st }}$ day of treatment before ingestion of the first capsule of CM-G, and once again after 28 days of daily administration. The patients were arranged into couples, with no more than two patients having the same $1^{\text {st }}$ or last day of ingestion. Vaccutainer tubes of $4.5 \mathrm{~mL}$ containing EDTA were used for collecting samples. Leukocyte counts were obtained by an automated method (Abbott Cell
Dyn 3200). Samples for comet assay were kept under refrigeration and protected from light during transport from the ICL to the Laboratory of Mutagenesis and Oncogenetics at the University of Londrina, Parana State, Brazil. Comet assays according Singh et al. (1988), with slight modifications, were conducted immediately after arrival of the samples in the laboratory. For the preparation of freshblood slides, $20 \mu \mathrm{L}$ of peripheral blood was mixed with $180 \mu \mathrm{L}$ of $0.5 \%$ low melting temperature agarose, and applied to microscope slides pre-coated with $1.5 \%$ normal melting temperature agarose. The slides were coverslipped and refrigerated for $5 \mathrm{~min}$ at $4{ }^{\circ} \mathrm{C}$. Duplicate coded slides were prepared for each sample, and the samples were processed in a randomized manner. Cells attached to the agarose matrix underwent lysis by immersion in an ice-cold solution containing $1 \%$ Triton $\mathrm{X}-100,10 \% \mathrm{DMSO}, 2.5 \mathrm{M}$ $\mathrm{NaCl}, 100 \mathrm{mM}$ EDTA, and $10 \mathrm{mM}$ Tris (pH 10.0), for at least $1 \mathrm{~h}$. The DNA was subsequently denatured for $20 \mathrm{~min}$ in an alkaline buffer $(300 \mathrm{mM} \mathrm{NaOH}$ and $1 \mathrm{mM}$ EDTA, final $\mathrm{pH}>13$ ) and electrophoresed for $20 \mathrm{~min}$ at $25 \mathrm{~V}$ and $300 \mathrm{~mA}(1.25 \mathrm{~V} / \mathrm{cm})$ in the same buffer. Subsequently, the slides were neutralized (400 mM Tris, $\mathrm{pH} 7.5)$ and fixed with $100 \%$ ethanol for $10 \mathrm{~min}$. For visual analysis, the slides were coded and stained with ethidium bromide $(20 \mathrm{mg} / \mathrm{mL})$, whereupon one hundred cells per patient were immediately scored at $400 \times$ magnification using a fluorescence microscope (Nikon-Brazil) with a blue (488 nm) excitation filter and yellow (515 nm) emission (barrier) filter. A single person person was assigned to analyzing the slides throughout the study by visual scoring. The cells were classified into four categories, each representing different degrees of DNA damage, these ranging from no visible migration (class 0 , undamaged cells) to maximum length comet (class 3, maximally damaged cells (DC) (Kobayashi et al., 1995; Forchhammer et al., 2008). DC frequency was obtained by first determining the number of undamaged (class 0 ) and DCs from each of classes 1,2 and 3, and then dividing this by the total number of cells analyzed in each treatment. The total score for 100 nucleoids was obtained by multiplying the number of cells in each class by the damage class (Manoharan and Banerjee, 1985): Total score $=$ $\left(0 \times n_{0}\right)+\left(1 \times n_{1}\right)+\left(2 \times n_{2}\right)+\left(3 \times n_{3}\right)$, where $n=$ number of cells in each class analyzed. Thus, the total score could range from 0 (100 cells presenting no damage) to 300 (all cells presenting class 3 damage). The damage reduction rates for each patient were determined based on scores observed before and after CM-G.

The results were analyzed with MEDCAL 9.2 software using the non-parametric Mann-Whitney test for DNA damage scores before and after CM-G treatment, and the Wilcoxon test for leukocyte counts, considering significance at $\mathrm{p} \leq 0.05$.

After completing treatment with $\mathrm{CM}-\mathrm{G}$, the number of returned capsules patients corresponded to the use of 28 capsules in the period. Subsequently, and through weekly 
contact, any side effects that could be associated with the use of CM-G were reported. This included typical symptoms of $\mathrm{PCa}$ under chronic treatment for testosterone inhibition, such as urinary symptoms and sexual dysfunction. The bone pain was reported by $90 \%$ of the patients. These effects of ADT occur due the loss in bone mineral density (BMD), worsened by advanced age (Diamond et al., 2004).

As to diet, all men mentioned the eating of red meat and salad on an average of five and three times a week, respectively. Furthermore, $65 \%$ of the patients reported unintentional weight-loss. When questioned, they responded that the reduction in food intake was attributed to symptoms such as change in taste, dryness of the mouth, vomiting, constipation and nausea. Except for two patients, who reported a decrease in nausea, these symptoms persisted during the treatment with $\mathrm{CM}-\mathrm{G}$.

Data for each patient, obtained from medical records and the individual questionnaire (Table 1), show the various individual lifestyle characteristics, such as smoking, age, alcoholism, and exposure to chemicals and radiation, that exerted an influence on the baseline of DNA damage.
The analysis of data on DNA damage scores, obtained both before and after treatment with CM-G, showed significant differences ( $\mathrm{p} \leq 0.05)$, with DNA damage reduction rates ranging from $18 \%$ to $87 \%$, with an average of $59 \%$ (Figure 1). The number of DCs in classes 1, 2 and 3 decreased significantly $(\mathrm{p} \leq 0.05)$ after CM-G treatment. On the other hand, there was an increase in the number of undamaged cells for all patients (Figure 2). Based on reports of increased stimulation of hematopoiesis by CM-G (Pospisil et al., 1991), the reduction in DNA damage could be attributed to an increase in the number of cells. In this way, the average numbers of white blood cells counted before $\left(1,789.25 \pm 766.1\right.$ per $\left.\mathrm{mm}^{3}\right)$ and after $(1,827.9 \pm 757.8$ per $\left.\mathrm{mm}^{3}\right) \mathrm{CM}-\mathrm{G}$ administration were not statistically different $(\mathrm{p}=0.63)$.

Five patients (25\%) were classified as current smokers. Nicotine, the most toxic component of cigarettes, is known to cause oxidative stress by inducing the generation of reactive oxygen species (ROS) (Sener et al., 2007). It is known that CM-G is a potent antioxidant, which, besides being effective even at very low concentrations, plays an important role in protecting biological membranes against

Table 1 - Data obtained from medical reports of 20 patients of the Cancer Institute of Londrina, Parana State, and from questionnaires completed after formal written consent and prior to administration of carboxymethyl-glucan (CM-G).

\begin{tabular}{|c|c|c|c|c|c|c|c|c|}
\hline \multirow[t]{2}{*}{ Patient } & \multirow[t]{2}{*}{ Age (years) } & \multirow[t]{2}{*}{ Ethnicity } & \multirow[t]{2}{*}{ TNM } & \multirow{2}{*}{$\begin{array}{c}\text { Goserelin } \\
\text { use (months) }\end{array}$} & \multicolumn{2}{|c|}{ Life style } & \multirow[t]{2}{*}{ Agrochemicals ${ }^{c}$} & \multirow[t]{2}{*}{ Radiotherapy } \\
\hline & & & & & Smoking ${ }^{\mathrm{a}}$ & Alcoholic $^{\mathrm{b}}$ & & \\
\hline 1 & 73 & African descendent & IV & 6 & no & yes & yes* & no \\
\hline 2 & 77 & European descendent & III & 6 & no & no & yes & no \\
\hline 3 & 84 & European descendent & IV & 7 & no & no & yes & yes \\
\hline 4 & 70 & Asian descendent & IV & 7 & no & no & yes & yes \\
\hline 5 & 63 & European descendent & IV & 12 & yes & yes & yes & no \\
\hline 6 & 71 & European descendent & IV & 6 & no & no & yes & no \\
\hline 7 & 71 & African descendent & III & 8 & no & no & yes* & no \\
\hline 8 & 63 & African descendent & III & 10 & no & yes & yes & yes \\
\hline 9 & 71 & European descendent & IV & 19 & no & no & yes & no \\
\hline 10 & 57 & European descendent & IV & 23 & yes & yes & yes & no \\
\hline 11 & 63 & European descendent & IV & 6 & no & no & no & no \\
\hline 12 & 79 & Asian descendent & IV & 36 & no & no & yes & no \\
\hline 13 & 67 & African descendent & IV & 10 & no & yes & yes & no \\
\hline 14 & 70 & African descendent & III & 6 & yes & no & yes & yes \\
\hline 15 & 68 & European descendent & III & 18 & no & yes & yes & no \\
\hline 16 & 63 & African descendent & IV & 6 & no & no & no & no \\
\hline 17 & 62 & Asian descendent & III & 5 & no & yes & yes & no \\
\hline 18 & 52 & European descendent & IV & 5 & no & no & yes & yes \\
\hline 19 & 76 & African descendent & IV & 6 & yes & no & yes & yes \\
\hline 20 & 80 & African descendent & III & 6 & yes & yes & no & no \\
\hline
\end{tabular}

${ }^{a}$ Patients who had quit smoking for less than one year are considered smokers.

${ }^{\mathrm{b}}$ Patients with behavior in alcohol-dependence.

${ }^{\mathrm{c}}$ Yes $=$ patients who have had contact or exposure to agrochemicals for $\geq 10$ years.

*Patients who reported intoxication by agrochemicals. 


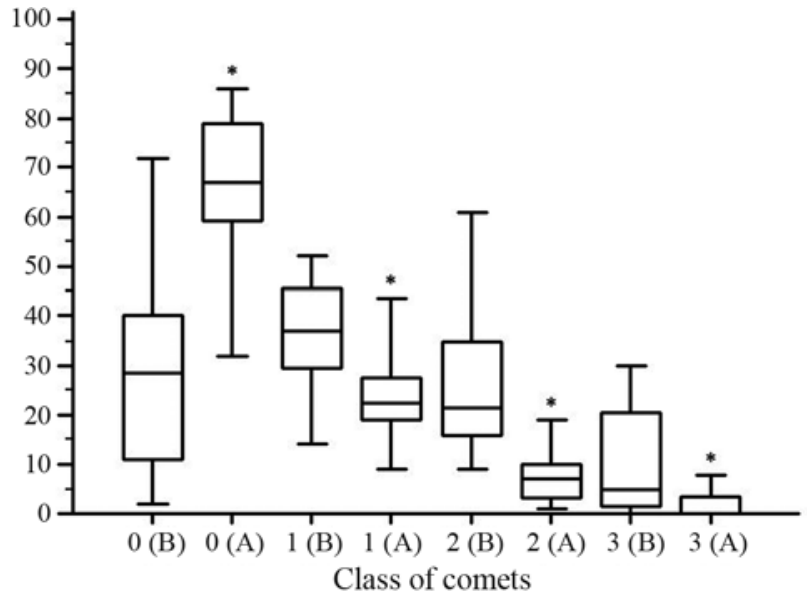

Figure 1 - Distribution of damaged cells into different classes of DNA damage, observed through comet assay, for patients with advanced prostate cancer before and after 28 days-treatment with carboxymethyl-glucan $(\mathrm{CM}-\mathrm{G}) ; \mathrm{B}=$ before and $\mathrm{A}=$ after. Bars denote minimum and maximum values observed in each damage-class, and the horizontal line inside the box representing the median; *denotes $\mathrm{p} \leq 0.05$, a statistically significant difference from the result before the treatment, as determined by the Mann-Whitney test.

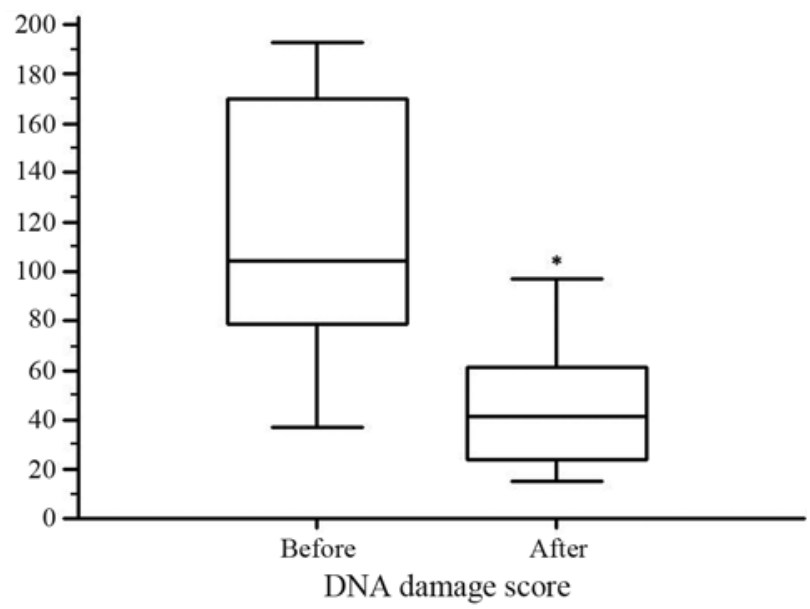

Figure 2 - DNA damage scores observed by comet assay in patients with advanced cancer prostate before and after 28 days-treatment with carboxymethyl-glucan (CM-G); $\mathrm{B}=$ before and $\mathrm{A}=$ after. Bars denote the minimum and maximum values observed for each score, the horizontal line inside the box representing the median. $*$ denotes $\mathrm{p} \leq 0.05$, a statistically significant difference between the results before and after treatment, as determined by the Mann-Whitney test.

adverse effects of free radicals (Babincová et al., 2002). Sener et al. (2007) suggested that the oral administration of soluble $\beta$-D-glucan from $S$. cerevisiae is effective against chronic nicotine intoxication, thereby reducing oxidative damage. Our data is consistent with these findings, since among the patients appraised, three smokers (5, 19 and 20) showed the three highest rates of reduction in DNA damage after treatment with CM-G.

Eight men (40\%) showed alcohol dependence. Ethanol itself does not induce lesions in the DNA of human lymphocytes, but its primary metabolite, acetaldehyde, evokes breaks in single- and double-stranded DNA (Singh et al., 1995). This, together with other factors that generate DNA damage, may have contributed to some of the highest rates of damaged DNA observed in these patients $1,5,8$ and 10 before CM-G.

Six patients (30\%) underwent radiotherapeutic treatment prior to starting ADT (Table 1) in order to control localized prostate tumors. The exposure of patients with cancer to therapeutic doses of radiation typically causes free-radical induced changes in the genomic DNA of lymphocytes, (Olinski et al., 1996). Morever, the generation of free radicals in the tissues may continue after exposure for several months (Robbins and Zhao, 2004). The high radical scavenging activity of CM-G from S. cerevisiae, with DS 0.8 , was confirmed by paramagnetic resonance spectroscopy (Kogan et al., 2005). Therefore, CM-G could be of help in decreasing the oxidative damage caused by radiotherapy.

Of the total number of patients, $85 \%$ had been occupationally exposed for at least 10 years previously, to a mixture of agrochemicals (Table 1), such as organophosphates, carbamates and organochlorines. This includes DDT and BHC, both banned in Brazil for over 20 years, due to high toxicity.

We believe that treatment with CM-G can be an efficient protection against DNA damage caused by mutagenic compounds through dismutagenic activity, either by its capability of blocking the action of damage-inducing agents, or by bio-antimutagenic activity, which exerts its effect by preventing damage or promoting DNA repair, since Oliveira et al. (2007) showed that this is a characteristic of $(1 \rightarrow 3)(1 \rightarrow 6)-\beta$-D-glucan from $S$. cerevisiae.

Prostate carcinogenesis may be related to chronic and acute prostate inflammation (De Marzo et al., 2007).The possible chemoprotective effect of antioxidants may be a form of protecting prostate cells from the DNA damage that normally occurs in the setting of inflammatory lesions (Smigel, 1998). Thus, there is a possibility that the DNA damage generated by the typical inflammation process was reduced through the administration of CM-G.

The results presented here highlight the protective effect of CM-G against DNA damage, which was shown for the first time in humans. These results suggest that $C M-G$ is potentially useful for improving the short-term survival of patients with advanced PCa. Studies are underway on the further beneficial effects of $\mathrm{CM}-\mathrm{G}$ administration, such as those related to immunomodulation, to assess the possibility of CM-G use improving prognosis in these patients.

\section{Acknowledgments}

The authors wish to thank the Londrina Cancer Institute for providing patient records and the Brazilian National Council of Scientific and Technological Development (CNPq) for financial support. 


\section{References}

Babincová M, Bacova Z, Machova E and Kogan G (2002) Antioxidant activity of carboxymethyl glucan: Comparative analysis. J Med Food 5:79-83.

Carrano AV and Natarajana AT (1988) Considerations for population monitoring using cytogenetic techniques. International Commission for Protection Against Environmental Mutagens and Carcinogens. Mutat Res 204:379-406.

Chen R and Seviour J (2007) Medicinal importance of fungal $\beta$-(1-3)(1-6)-glucans. Mycol Res 3:635-652.

Chorvatovicová D, Machova E and Sandula J (1996) Effect of ultrasonicated carboxymethylglucan on cyclophosphamide induced mutagenicity. Mutat Res 371:115-120.

De Marzo AM, Platz EA, Sutcliffe S, Xu J, Grönberg H, Drake CG, Nakai Y, Isaacs WB and Nelson WG (2007) Inflammation in prostate carcinogenesis Nat Rev Cancer 7:256-269.

Demir G, Klein HO, Mandel-Molinas N and Tuzuner N (2007) $\beta$-glucan induces proliferation and activation of monocytes in peripheral blood of patients with advanced breast cancer. Int Immunopharm 7:113-116.

Di Luzio NR, Williams DL, Mcnamee RB, Edwards BF and Kithama A (1979) Comparative tumor-inhibitory and antibacterial activity of soluble and particulate glucan. Int J Cancer 24:773-779.

Diamond TH, Bucci J, Kersley JH, Aslan P, Lynch WB and Bryant C (2004) Osteoporosis and spinal fractures in men with prostate cancer: Risk factors and effects of androgen deprivation therapy. J Urol 172:529-532.

Forchhammer L, Br®uner EV, Folkmann JK, Danielsen PH, Nielsen C, Jensen A, Loft S, Friis G and Møller P (2008) Variation in assessment of oxidatively damaged DNA in mononuclear blood cells by the comet assay with visual scoring. Mutagenesis 23:223-231.

Hellerstedt BA and Pienta KJ (2002) The current state of hormonal therapy of prostate cancer. Cancer J Clin 52:154-179.

Kobayashi H, Sugiyama C, Morikawa Y, Hayashy M and Sofuni $\mathrm{T}$ (1995) A comparison between manual microscopic analysis and computerized image analysis in the single cell gel electrophoresis assay. MMS Commun 3:103-115.

Kogan G, Stasko A, Bauerova K, Polovka M, Soltes L, Brezova V, Navarova J and Mihaloa D (2005) Antioxidant properties of yeast $(1 \rightarrow 3)-\beta$-D-glucan studied by electron paramagnetic resonance spectroscopy and its activity in the adjuvant arthritis. Carbohydrate Polym 61:18-28.

Magnani M, Calliari CM, de Macedo Jr FC, Mori MP, de SyllosCólus IM and Castro-Gomez RJH (2009) Optimized methodology for extraction of (1-3)(1-6)- $\beta$-D-glucan from Saccharomyces cerevisiae and in vitro evaluation of the cytotoxicity and genotoxicity of the corresponding carboxymethyl derivative. Carbohydrate Polym 78:658-665.

Manoharan K and Banerjee MR (1985) $\beta$-carotene reduces sister chromatid exchange induce chemical carcinogens in mouse mammary cells in organ culture. Cell Biol Int Rep 9:783789 .

Miadaková E, Svidová S, Vlchová V, Duhová V, Prazmariová E, Tothová K, Nadová S, Kogan G and Rauko P (2005) The role of natural biopolymers in genotoxicity of mutagens carcinogens elimination. Biomed Pap Med Fac Univ Palacky 149:493-496.

Olinski R, Zastawny TH, Foksinsti M, Windorbsk W, Jaruga P and Dizdaroglu M (1996) DNA base damage in lymphocytes of cancer patients undergoing radiation therapy. Cancer Lett 106:207-215.

Oliveira RJ, Matuo R, da Silva AF, Matiazi HJ, Mantovani MS and Ribeiro LR (2007) Protective effect of $\beta$-glucan extracted from Saccharomyces cerevisiae against DNA damage and cytotoxicity in wild-type (k1) and repair-deficient xrs5 CHO cells. Toxicol in Vitro 21:41-52.

Pospisil M, Sandula J, Pipalova I, Hofer M and Viklicka S (1991) Hemopoiesis stimulating and radioprotective effects of carboxymethylglucan. Physiol Res 40:377-80.

Rice PJ, Adams EL, Ozment-Skelton T, Gonzalez AJ, Goldman MP, Lockhart BE, Barker LA, Breuel KF, DePonti WK, Kalbfleisch JH, et al. (2005) Oral delivery and gastrointestinal absorption of soluble glucans stimulate increased resistance to infectious challenge. J Pharmacol Exp Ther 314:1079-1086.

Robbins ME and Zhao W (2004) Chronic oxidative stress and radiation-induced late normal tissue injury: A review. Int $\mathbf{J}$ Radiat Biol 80:251-259.

Sener G, Toklu HZ and Cetinel S (2007) $\beta$-Glucan protects against chronic nicotine-induced oxidative damage in rat kidney and bladder. Environ Toxicol Pharm 23:25-32.

Singh NP, Lai H and Khan A (1995) Ethanol-induced singlestrand DNA breaks in rat brain cells. Mutat Res 345:191-196.

Singh NP, McCoy MT, Tice RR and Schneider EL (1988) A simple technique for quantification of low levels of DNA damage in individual cells. Exp Cell Res 175:184-491.

Slamenová D, Laaj J, Kriskova L, Kogan G, Sandula J, Bresgen N and Eckl P (2003) Protective effects of fungal (1-3)- $\beta$ D-glucan derivatives against oxidative DNA lesions in V79 hamster lung cells. Cancer Lett 198:153-160.

Smigel K (1998) Vitamin E reduces prostate cancer rates in Finnish trial: U.S. considers follow-up. J Natl Cancer Inst 90:416-417.

Xu J, Liu W, Yao W, Pang X, Yin D and Gao X (2009) Carboxymethylation of a polysaccharide extracted from Ganoderma lucidum enhances its antioxidant activities in vitro. Carbohydrate Polym 78:227-234.

\section{Internet Resources}

American Joint Committee on Cancer/ Union International Against Cancer (AJCC/UICC)

http//www.cancerstaging.org (May, 2010).

National Cancer Institute of Brazil (INCA), http//www.inca.gov.br (April, 2010).

Associate Editor: Carlos F.M. Menck

License information: This is an open-access article distributed under the terms of the Creative Commons Attribution License, which permits unrestricted use, distribution, and reproduction in any medium, provided the original work is properly cited. 